\title{
Encoding, Decoding and Cultural Identity: An Analysis of Culture Communication of Confucius Institutes"
}

\author{
Tianzheng Wang \\ School of Journalism and Communication, China University of Political Science and Law, Beijing, China \\ wangtianzheng@gmail.com
}

\begin{abstract}
The Confucian culture communication is a process of culture reproduction. The process is the re-encoding on Chinese Culture resources, aimed to strengthen the culture identity in different countries. Different cultural contexts affect culture decoding; culture identity is the result of interaction between cultural tradition and different social forces. This study, through analyzing a sample of Confucius Institutes in the United States, Japan, Russia, Thailand and Lebanon, finds the difference of cultural reproduction of Confucius Institutes in five countries above mentioned is very small, however, the difference of students' attitude and behavior to Chinese culture is obviously big. The Chinese Culture identity in different culture circles, especially in the Confucian culture circle and non-Confucian circle, differs greatly. It is easier for the students in the Confucian culture circle to understand and approve Chinese culture than the students in non-Confucian culture circle; it is easier for the students in non-Confucian culture circle to absorb Chinese material culture and Chinese behavior culture than Chinese spiritual culture.
\end{abstract}

Index Terms - Cultural Identity, Culture communication, Confucius Institute, Encoding, Decoding

\section{Introduction}

Confucius Institute is the non-profitable public institution which aims to promote Chinese language and culture in other countries. The services Confucius Institutes offer include teaching Chinese language, training Chinese language teachers, sharing Chinese language teaching resources, organizing Chinese language test and certification of Chinese language teaching qualification, holding Chinese culture activities, providing information consulting on China's education and culture. Because Confucius Institutes are organized and guided by Hanban, which is an agency under the Chinese national ministry of education, the Confucius Institutes' activities of Chinese language teaching and culture communication are questioned and disputed by some groups. According to them, the institutes could increase China's "soft power" and help it project an image of itself as a benign country. Concerns exist about a "Trojan horse" effect the institutes may bring about (Paradise, 2009).

The purpose of this study is to explore cultural identity during the progress of Chinese language teaching and its related culture communication activities in Confucius Institutes: What are the Confucius Institutes doing? How do the students cognize, understand and experience Chinese culture? How to understand the students' attitude to Chinese culture?

\section{The Culture Communication of Confucius Institutes}

Culture communication is a process of culture reproduction. It aims to realize the cultural identity through reencoding of available cultural resources. The re-encoding of Chinese culture is focused on the explanation of the meaning of Chinese language, as well as the implication of China material culture, behavior culture and spiritual culture, which helps the beginners know basic Chinese culture, such as the filial piety as part of Chinese culture.

\section{A. Chinese language Teaching}

Based on the current level and learning needs of the local students, Confucius Institutes choose suitable teaching material. The curriculum is usually divided into required courses, elective courses and professional courses, among which, the required courses include intensive reading, listening comprehension, spoken Chinese, extensive reading, writing, etc.; Elective courses include Chinese calligraphy, tourism and geography, Chinese brush drawing, the Peking Opera, etc.; Professional courses include business translation, economic and trade writing, etc. Because most students in Chinese language learning are beginners, the main courses offered by Confucius Institutes in different countries are Chinese language study which focuses on Chinese words and grammar. In some countries or regions with good Chinese communication environment, such as Singapore, where the students have certain Chinese foundation, the local Confucius Institutes will teach some Confucian classic thoughts and classical Chinese poetry, promoting students' understanding of the core idea of Confucian culture and Chinese modern culture which is influenced deeply by the Confucian culture.

Confucius Institutions arrange Chinese language courses according to local demand for the study. The education institutions and residents in Chicago hope Confucius Institutions will not only teach Chinese language, but also train local Chinese language teachers, in order to offer quality Chinese language courses in local secondary and primary schools, and thus the Confucius Institute of Chicago not only open Chinese language, Chinese history, Chinese culture, and business courses for primary and secondary school and adults as well, but also offer all kinds of special training programs and lectures to Chinese teachers in Chicago city and Northern Illinois area, who are teaching Chinese language to the

\footnotetext{
* This research is supported by Program for Young Innovative Research Team in China University of Political Science and Law, and Program for Excellent Young Scholar Development in China University of Political Science and Law.
} 
students from kindergarten to 16-grade level. Similarly, after a survey on Chinese language teaching in London and the surrounding areas, the Confucius Institute in London pays great attention to training local Chinese language teachers, and launches model lessons, teacher training programs and seminars as well, to enhance the Chinese teaching to elementary and secondary schools. In Italy, the Confucius Institute of Rome University offers a wide range of Chinese courses to the students in view of their common interest in Chinese history and traditional culture. The courses include modern Chinese language, ancient Chinese language, Chinese classical literature, Chinese modern literature, Chinese ancient history, Chinese modern history, Chinese arts, Chinese classic music history and Chinese law, etc. There are more economic interactions and exchanges between Singapore and China than ever, so local Singaporeans have high level of enthusiasm of learning Chinese in local Confucius Institute, and they also hope that their children will learn Chinese, in order to have better chances and advantages for their future. In Singapore, Confucius Institute at Nanyang Technological University not only offers Chinese language and culture courses for enterprise Groups, financial and business institutions, and Southeast Asia regional companies, but also provides training courses for the cultivation of Chinese language teachers for local primary and secondary schools.

\section{B. Chinese culture activities}

In addition to the daily Chinese language teaching, Confucius Institutes all over the world held various Chinese culture activities to promote local people's understanding of Chinese culture. Because Asian countries have similarities in culture, and the economic and trade contacts with China are frequent, it is easier for their nationals to understand Chinese culture, especially the Confucian culture. Confucius Institutes in Asian countries usually organize culture activities with certain depth and practicability. Take the example of Seoul Confucius Institute in South Korea, China-Korea cultural forum, as well as the relevant information of China's trade and study, will be organized and offered to the local residents upon their requirement. Confucius Institution at Nanyang Technological University in Singapore organizes Chinese language seminars and holds culture activities of playing Chinese film and TV.

Because most people in western countries are not familiar with the Chinese culture, the culture activities of Confucius Institutes there are designed to cultivate interest in and understanding Chinese culture. Confucius Institutes in many western countries, such as the Free University at Berlin, University of Poitiers in France etc, have been actively holding lectures about Chinese history and culture, organizing Chinese calligraphy and painting exhibition, tea art performance and so on. They also hold celebrations activities during the Chinese traditional festivals, in order to introduce the traditional Chinese culture to students and local residents.

\section{Method}

This study is based on a secondary analysis of a large survey conducted by Young Innovative Research Team in Shanghai International Studies University. Specifically, the study used the survey of International Communication Effects of Chinese Culture, which is based on a probability sample of 565 students of 16 Confucius Institutes in U.S., Japan, Russia, Thailand and Lebanon. Respondents were offered incentives to fill out a lengthy questionnaire that measured their demographics, cognition and attitude to Chinese material culture, behavior culture and spiritual culture.

\section{Procedure and Results}

\section{A. Recognition, attitude and behavior to Chinese material culture and behavior culture}

The questionnaire is designed to conduct survey on the students' cognition, attitude and behavior to the representative material culture and behavior culture. Material culture is represented by tea, Chinese food, the Great Wall, Terra Cotta Warriors, and dumplings; Behavior culture is represented by Taijiquan, traditional Chinese medicine, Chinese kung fu, dragon and lion dance, Chinese calligraphy, and Chinese poetry. For each item, each student was asked three questions: do know it or not, do you like it or not, did you ever contact and experience it or not. Answer "yes" is assigned a score of " 1 "and answer "no" is assigned a score of " 2 ", which means the closer to " 1 " the average score is, the higher level of cognition, attitude and experience of Chinese culture the students have.

The students of 16 Confucius Institutes in five countries indicated their knowledge and likeness to five material cultures and six behavior cultures mentioned in the questionnaire. There are high levels of cognition to the Great Wall $(\mathrm{M}=1.03$, $\mathrm{SD}=0.167)$, Chinese food( $\mathrm{M}=1.04, \mathrm{SD}=0.215)$ and Chinese Kung $\mathrm{Fu}(\mathrm{M}=1.05, \mathrm{SD}=0.253)$, while the level of cognition to Chinese poetry $(\mathrm{M}=1.34, \mathrm{SD}=0.493)$ and Terra-Cotta Warriors $(\mathrm{M}=1.26, \mathrm{SD}=0.453)$ are low. The high cognition to the Great Wall and Chinese Kung Fu mainly come from news coverage and movies, and the high cognition to Chinese food is because there are so many Chinese restaurants in the five countries. While the cognition to Chinese poetry is very low because there is little chance to read Chinese poetry for students whose Chinese foundation are weak. Though TerraCotta Warriors is world famous cultural heritage like the Great Wall, it is less reported by mass media in the five countries than the Great Wall, and thus the level of cognition is low. However, the Standard Deviation of Chinese poetry and TerraCotta Warriors is big, which means the difference in cognition level is big.

The survey indicates that the Great Wall $(\mathrm{M}=1.02$, $\mathrm{SD}=0.178)$, Terra-Cotta Warriors $(\mathrm{M}=1.07, \quad \mathrm{SD}=0.315)$, Chinese Calligraphy $(\mathrm{M}=1.09, \mathrm{SD}=0.318)$ achieve the top three highest scores, which represents the students like them most among all the cultural items. On the contrary, Taijiquan $(\mathrm{M}=1.26, \mathrm{SD}=0.461)$, Traditional Chinese medicine (Mean: 1.26, $\mathrm{SD}=0.459$ ) achieves the lowest scores, which indicates the students like them least as compared to other cultural items. Even though the Great Wall, Chinese food, and Chinese 
Kung Fu have high level of cognition, however, it does not bring high degree of likeness from the students. The standard deviation of Terra-Cotta Warriors is very high, which means likeness level of some students who maybe have field visit is very high so as to lead a high average score of likeness. Many Confucius Institutes offer Chinese Calligraphy courses and organize related experience activities, which promotes the students' level of likeness to Chinese Calligraphy.

According to the survey, the students have the highest level of contact or experience on Chinese food ( $\mathrm{M}=1.05, \mathrm{SD}$ $=0.256)$, tea $(\mathrm{M}=1.06, \mathrm{SD}=0.275)$, dumplings $(\mathrm{M}=1.26$, $\mathrm{SD}=0.488)$ and the Chinese calligraphy $(\mathrm{M}=1.26, \mathrm{SD}=$ $0.455)$, however, low level of contact or experience on Terra Cotta Warriors $(\mathrm{M}=1.81, \mathrm{SD}=0.441)$, the Great Wall $(\mathrm{M}=$ $1.69, \mathrm{SD}=0.495)$ and traditional Chinese medicine $(\mathrm{M}=1.60$, $\mathrm{SD}=0.53$ ). Chinese food and tea have become necessary food ingredients in the five countries, and dumplings and Chinese calligraphy often appear in the Confucius Institutes' courses or related group activities, which explains why the students have high degree of contact and experience. Because many students have not ever been to China before, they have low degree of contact and experience level on Terra Cotta Warriors and the Great Wall. Traditional Chinese medicine has yet to be accepted and recognized, as judged by international medical standard, and thus the contact and experience level of the students on it is very low.

\section{B. Attitude to spiritual culture}

According to the core value of the Confucian culture as represented by "filial piety, frugality, propriety, diligence, respect eldership, prudence and modesty", 7 questions (Q1: Treat others with propriety; Q2: Filial piety to parents is the person's basic requirement; Q3: Be modest to compliment from others; Q4: Hard work is the premise of success; Q5:
Talk and behave with caution and prudence; Q6: Follow instructions from superiors and show respects to elders; Q7: It is a virtue to lead a frugal life) were designed to test the understanding of the students' cultural identity(Table I), and each question has five options to choose from which include "strongly disagree, disagree, neutral, agree, strongly agree" by assigning a score 1-5 each respectively. The higher score represents the higher degree of cultural identity. According to the observation, students score highest to "propriety", and the standard deviation of which is the lowest, which indicates that "propriety " gains the highest cultural identity; while the students score lowest to "frugality", and the standard deviation of which is the highest, which indicates that the cultural identity to "frugality" is the lowest.

The test result reflects the difference in traditional culture between China and other countries. For each item the score of Thailand are higher than the average, and the standard deviation is lowest, which shows students of Thailand have highest identity of Confucian culture than students from other four countries. It is explained by the fact that Thailand and China belong to the same Asian Confucian culture circle. However, even though Japan in the same Asian Confucian culture circle, its scores is lower than average and the standard deviation are not very high, which suggests that students from Japan, to some extent, disagree with Confucian culture. This difference is related to the fact Japan has achieved rapid economic development in recent years and tried to learn western culture in order to promote its economic growth. The other three countries from non-Confucianism culture circle have high degree of cultural identity to the items which are closed to their own culture, on the contrary, lower identification level to the items which is far different from their own culture.

TABLE I Attitude to Chinese spiritual culture

\begin{tabular}{|c|c|c|c|c|c|c|c|c|c|c|c|c|}
\hline & The total sample & \multicolumn{2}{|c|}{ U.S. } & \multicolumn{2}{c|}{ Thailand } & \multicolumn{2}{c|}{ Lebanon } & \multicolumn{2}{|c|}{ Russia } & \multicolumn{2}{c|}{ Japan } \\
\cline { 2 - 15 } & $\mathrm{M}$ & $\mathrm{SD}$ & $\mathrm{M}$ & $\mathrm{SD}$ & $\mathrm{M}$ & $\mathrm{SD}$ & $\mathrm{M}$ & $\mathrm{SD}$ & $\mathrm{M}$ & $\mathrm{SD}$ & $\mathrm{M}$ & $\mathrm{SD}$ \\
\hline Q1 & 4.67 & 0.614 & 4.65 & 0.772 & 4.79 & 0.515 & 4.72 & 0.666 & 4.64 & 0.617 & 4.24 & 0.429 \\
\hline Q2 & 4.37 & 0.902 & 3.65 & 0.998 & 4.92 & 0.382 & 3.47 & 0.872 & 4.49 & 0.898 & 4.10 & 0.569 \\
\hline Q3 & 4.36 & 0.848 & 4.13 & 0.973 & 4.71 & 0.538 & 4.24 & 0.959 & 4.14 & 1.027 & 3.95 & 0.682 \\
\hline Q4 & 4.33 & 0.888 & 3.89 & 1.104 & 4.79 & 0.488 & 3.88 & 1.022 & 4.39 & 0.803 & 3.73 & 0.677 \\
\hline Q5 & 4.23 & 0.893 & 4.01 & 1.052 & 4.50 & 0.764 & 4.24 & 0.811 & 4.26 & 0.837 & 3.44 & 0.760 \\
\hline Q6 & 4.08 & 0.917 & 4.06 & 0.998 & 4.40 & 0.688 & 3.74 & 1.054 & 4.00 & 1.011 & 3.54 & 0.737 \\
\hline Q7 & 4.04 & 0.972 & 4.05 & 0.917 & 4.60 & 0.590 & 3.63 & 1.033 & 3.32 & 1.065 & 3.67 & 0.741 \\
\hline
\end{tabular}

\section{Conclusions}

According to the survey, basically the students of 16 Confucius Institutes in five countries recognize Chinese culture to a certain level, however, they can't completely identify the Chinese culture, which needs solid foundation of Chinese language and Chinese historical and cultural background to understand well. Chinese cultural identity is more influenced by the existing culture of host country, the local politics, economy, society, and environment as well. In this sense, the objective of Confucius Institutes is mainly to teach Chinese language as priority rather than to spread the Chinese culture. 
Firstly, because the major teaching purpose is to teach Chinese language and Chinese representative material culture, behavior culture and spiritual culture, the content and methods of "Cultural Reproduction" of Confucius Institutes in different countries have very little difference, and the students have cultural identity to the representative material culture and behavior culture, however, cultural identity only to the spiritual culture which complies with their own cultural values. The major objective of Confucius Institutes is to teach Chinese language and to arouse interest in learning Chinese language. Priority is given to teaching the simple and basic items of daily life in Chinese, e.g. food, drink, transportation etc. When explaining Chinese words, the teachers of Confucius Institutes may introduce some relevant Chinese culture, e.g. when the students learn Chinese words “长城” (the Great Wall), the teacher will explain the separate meaning of “长” and “城”, and the combined meaning that demonstrates exactly the characteristics of the Great Wall and its function, and then introduce the history of the Great Wall and related legends. This study examines the material culture and behavior culture as the iconic Chinese culture, which is the common teaching content of the 16 Confucius Institutes in five countries, and which the students have higher cognitive degree and identity level. Even although they have no contact or never experience some Chinese culture before, such as the world cultural heritage of the Terra-Cotta Warriors, they show high level of identity; and for some Chinese culture in which there are some disputes in judging its value, such as traditional Chinese medicine, the identity level is relatively low. The objective of Confucius Institutes is mainly to teach Chinese language, help students learn how to express the familiarized items or ideas in Chinese, introduce some Chinese culture in the process of Chinese language teaching, and expand students' existing knowledge of China. Furthermore, culture activities organized by Confucius Institutes are very important for students to deeply understand and identify Chinese culture, however, their attitudes to Chinese culture still come from the existing understanding of their own culture.

Secondly, different cultural circles and different realistic environments lead to different culture decoding. The students' cognition, attitude and behaviour to Chinese culture are different because of the different cultural circles in which the students live. Cultural identity to Chinese culture in different cultural circles, especially in the Confucian cultural circle and the non-Confucian cultural, differs greatly. Generally the students in the Confucian culture circle are more likely to accept the Confucian culture, but affected by the current social environment. Even though Thailand and Japan belong to the same Confucian cultural circle, and Confucian culture has deep influence on the development of both countries, as evidenced by the existence of much excellent traditional Confucian cultural traditions, the attitude to Confucian spiritual culture is quite different in the two countries. The cognition of the students from Thailand to Confucian spiritual culture is higher than the average level, however, the Japanese students' cognition is lower than average. The reason is that
Japan has been actively learning from western countries and conducted frequent economic and cultural exchange with western countries after the Second World War. With the development of economy, Japanese people has accepted some ideas from western culture and gradually disagree with some traditional Confucian culture. As the economy is moving forward, China is also experiencing the similar situation with Japan that the young people begin to disagree with some ideas of traditional Confucian culture. For the representative Chinese material culture and behaviour culture, it has higher level cognition in countries and cultural cycles where it has higher changes of appearance. For example, Chinese restaurants in the United States and Russia are quite common, while they are few in Lebanon, and then the students' cognitive level of United States and Russia is higher than Lebanon. Meeting domestic cultural criterion, Chinese culture which meets local cultural criteria will get higher cultural identity than usual, which explains the high average identity level to "propriety", for that it is a cultural value commonly recognized and respected by all the sample countries of the survey.

Cultural identity is the product of the interaction of all kinds of social powers. Confucius Institutes, since their initial establishment, have been questioned by different groups of people. Some people link them with communism, tools of propaganda, and some other people thinks Confucius college is used by Chinese government to be symbol of its soft power. All these endow the culture communication of Confucius Institutes with different meanings. Just for now, the main objective of the Confucius Institutes is to teach Chinese language and train Chinese language teacher, however, what the Confucius Institutes' plan is unclear yet when the students have certain foundation of Chinese language or when the foreign Chinese teachers have certain professional level of Chinese language. To be sure, it is a tortuous way for the Confucius Institutes to get cultural identity from other countries.

\section{References}

[1] Chinese culture connection, "Chinese value and the search for culture free dimensions of culture," Journal of Cross-culture Psychology, vol.18, no.2, pp.147-159, 1987.

[2] Falk Hartig(2012), "Confucius Institutes and the Rise of China," Journal of Chinese Political Science, 17(1), 53-76.

[3] James F. Paradise , "China and International Harmony: The Role of Confucius Institutes in Bolstering Beijing's Soft Power”, Asian Survey, vol.49,no.4, pp.649 - 660, 2009.

[4] Jeffrey Gil, "The Promotion of Chinese Language Learning and China's Soft Power," Asian Social Science, vol.4, no.10, pp.116 -122, 2008.

[5] Joshua Kanlantzick, Charm offensive: how China's soft power change the world, New Haven: Yale University Press, 2007.

[6] Rui Yang, "Soft power and higher education: an examination of China's Confucius Institutes," Globalisation, Societies and Education, vol.8, no.2, pp.235-245, 2010.

[7] Sheng Ding and Robert A. Saunders, "Talking up China: An Analysis of China's Rising Cultural Power and Global Promotion of the Chinese Language," East Asia, vol.23, no.2, pp.7-33, 2006.

[8] Wu Ying, "On the international communication effects of Chinese culture”, Zhejiang Social Science, vol.2012, no.4, pp.144-151, 2012. 